\title{
Penerapan Metode K-Nearest Neighbor (KNN) Untuk Menentukan Ikan Cupang Dengan Ekstraksi Fitur Ciri Bentuk Dan Canny
}

\author{
Fajar Shidiq ${ }^{1}$, Eka Wahyu Hidayat ${ }^{2}$, Neng Ika Kurniati ${ }^{3}$ \\ 1.2.3Informatika, Fakultas Teknik, Universitas Siliwangi, Tasikmalaya, Indonesia

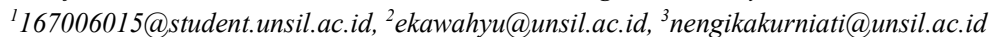

\section{INFORMASI ARTIKEL}

Sejarah Artikel:

Diterima Redaksi: 31-05-2021

Revisi Akhir: 10-06-2021

Diterbitkan Online: 30-09-2021

\begin{tabular}{l} 
KATA KUNCI \\
\hline Ikan Cupang, \\
K-Nearest Neighbor, \\
Deteksi Tepi, \\
Canny
\end{tabular}

\section{KORESPONDENSI}

Telepon: 085320118780

E-mail:167006015@student.unsil.ac.id

\begin{abstract}
Betta fish are known as fighting fish, aggressive and like to attack several types of betta fish have attractive body colors, beautiful fin shapes, calm and authoritative movements. However, there are still many people who are wrong in distinguishing the types of their pet betta fish, especially for those who have just bought. The purpose of this study is to apply the K-Nearest Neighbor method and edge detection with the Canny method in determining the type of betta fish. Canny is known as optimal edge detection, this algorithm provides a low error rate. The combination of K-Nearest Neighbor with Canny produces a fairly high accuracy for determining the type of betta fish, which is an average of $68.5714 \%$, for training data with a total of 70 betta fish data, and $70 \%$, for test data with a total of 20 betta fish data.
\end{abstract}

\section{Pendahuluan}

Ikan Cupang (Betta Fish) dikenal sebagai ikan petarung, agresif dan suka menyerang. Beberapa jenis ikan cupang memiliki warna tubuh yang menarik, bentuk sirip indah, gerakan tenang dan berwibawa, sehingga banyak dipelihara sebagai ikan hias dan juga ikan aduan. Habitat asli ikan cupang tersebar di wilayah Asia Tenggara, termasuk Indonesia. Ikan ini banyak ditemukan di rawarawa, danau, dan lubuk. Kebanyakan penggemar mengenal jenis ikan cupang dengan berbagai sebutan nama, seperti: Crowntail, Doubletail, Dumboear, Halfmoon, Plakat, Slayer, Wild dan berbagai variasi silangannya. Nama nama tersebut ditentukan dari bentuknya, misalnya Halfmoon memiliki sirip yang membentuk setengah lingkaran, Crowntail memiliki sirip yang bergerigi runcing seperti sisir [1].

Masih banyak orang yang keliru dalam membedakan jenis ikan cupang peliharaannya terutama bagi yang baru membeli. Seperti contohnya ikan cupang hias ditentukan berdasarkan bentuk fisik, warna, gerakan dan mentalnya.
Sedangkan untuk kriteria ikan cupang aduan juga hampir sama seperti kriteria yang ditentukan untuk ikan cupang hias, tetapi ikan cupang aduan ini cenderung memiliki sifat yang lebih agresif daripada ikan cupang hias.

Ikan hias akan menjadi sektor yang paling diminati untuk pembudidaya ikan di Indonesia. Selain ikan hias, yang banyak diminati para penggemar ikan adalah ikan cupang, karena warna dan corak yang indah. Sehingga banyak dijadikan sebagai salah satu jenis hewan peliharaan karena memiliki kelebihan pada warna yang dihasilkannya berbeda dengan ikan hias jenis lain. Berbagai warna warni indah pada ikan cupang dasarnya dihasilkan oleh sel - sel pigmen (chromatophore) yang terletak pada kulitnya. Ikan ini merupakan salah satu jenis hewan peliharaan yang mempunyai daya tarik yang dimunculkan pada beberapa bagian tubuhnya seperti bentuk ekor, sirip, dan warnanya [2]. Keindahan bentuk sirip dan warnanya sangat menentukan nilai jual. Warna pada ikan cupang memiliki fungsi yang signifikan, yaitu sebagai pengenal jenis dari tampilan pola dan corak warna pada tubuhnya juga sebagai 
proteksi diri dari ancaman pemangsanya. Ikan cupang menjadi daya tarik para penggemar ikan hias mulai dari anak kecil hingga mereka yang sudah dewasa.

Agar lebih mudah dalam menentukan jenis ikan cupang, diusulkan klasifikasi jenis ikan cupang menggunakan metode K-Nearest Neighbor (K-NN). K-NN dipilih karena dapat digunakan untuk klasifikasi objek berdasarkan data pembelajaran yang jaraknya paling dekat dengan objek tersebut sehingga hasilnya bisa lebih akurat [4]. Klasifikasi yang dilakukan diimplementasikan dalam suatu aplikasi atau program komputer menggunakan Matlab. Matlab merupakan salah satu tools yang mendukung pemrograman yang dikhususkan untuk kebutuhan komputasi teknis, visualisasi dan pemrograman seperti komputasi matematik, analisis data, pengembangan algoritma, simulasi, pemodelan dan grafik perhitungan [3].

Sebelum masuk ke tahap klasifikasi citra, dilakukan tahap ekstraksi terlebih dahulu menggunakan metode deteksi tepi Canny. Canny merupakan suatu algoritma deteksi tepi yang dilakukan dengan pendekatan konvolusi terhadap fungsi matriks gambar dan operator gaussian [5], Metode Canny dipilih karena sangat sesuai dengan ekstraksi citra yang dilakukan berdasarkan bentuk sirip dan ekor ikan cupang, setelah semua tahapan selesai maka akan dilakukan pengujian kinerja proses sebuah algoritma dengan cara menghitung jumlah hasil output yang sesuai dan tidak sesuai berdasarkan klasifikasi yang telah dilakukan baik pada data latih maupun data uji, pengujian ini bertujuan untuk mengetahui nilai akurasi yang dihasilkan [6].

\section{Ulasan Penelitian Terkait}

Penelitian yang dilakukan oleh Andrian, dkk (2019) mencoba menerapkan metode deteksi tepi Canny Dan KNearest Neighbor dalam menentukan jenis kupu - kupu. Hasil penelitiannya, menunjukan bahwa implementasi sistem dalam mengidentifikasi kupu - kupu dengan menggunakan ekstraksi fitur canny edge detection dan klasifikasi k-nearest neighbor telah berhasil di implementasikan dengan tingkat akurasi tertinggi diperoleh pada pengujian pada nilai $\mathrm{k}=5$ yaitu sebesar $80 \%$ dengan tingkat kesalahan klasifikasi sebesar 20\%. Waktu yang diperlukan sistem pada tahap ekstraksi sebesar 26 detik yang dibagi menjadi data latih sebanyak 420 citra sebesar 18 detik dan data uji sebanyak 180 citra sebesar 8 detik. Waktu yang diperlukan sistem pada tahap klasifikasi sebanyak 180 citra sebesar 2 detik.

Penelitian yang dilakukan oleh Surahman, dkk (2017) mencoba menerapkan metode Canny \& K-Nearest Neighbor (KNN) untuk deteksi jenis pempek. Hasil pengujian dari penelitian tersebut menunjukan bahwa data citra pempek pada skenario normal mendapatkan rataan tingkat akurasi mulai dari $30-100 \%$, pengujian dengan nilai $\mathrm{K}=1$ mendapatkan tingkat akurasi lebih tinggi, perbedaan ukuran piksel data citra mempengaruhi tingkat akurasi yang diperoleh, penambahan noise pada citra mempengaruhi tingkat akurasi yang diperoleh, perbedaan resolusi kamera pada citra mempengaruhi tingkat akurasi yang diperoleh.
Penelitian yang dilakukan oleh Ashari (2019) mencoba menerapkan metode Prometee dalam proses perangkingan juara kontes ikan cupang. Penelitian yang dilakukan oleh Setiawan (2017) mencoba menerapkan metode Naive Bayes Untuk Menentukan Jenis Ikan Cupang Hias.

\section{Metodologi}

\subsection{Pengolahan Citra}

Pengolahan citra adalah istilah umum untuk berbagai teknik yang keberadaannya untuk memanipulasi dan memodifikasi citra dengan berbagai cara [7]. Pengolahan citra merupakan proses pengolahan sinyal yang inputnya berupa citra dan akan menghasilkan output citra ataupun sekumpulan karakteristik atau yang berhubungan dengan citra untuk tujuan tertentu. Tujuan dari pengolahan citra pada awalnya adalah untuk memperbaiki kualitas citra, namun seiring dengan perkambangan dunia komputasi yang ditandai dengan meningkatnya kapasistas serta kecepatan proses komputer dan munculnya ilmu komputasi yang memungkinkan kita untuk mengambil informasi dari suatu citra, maka pengolahan citra tidak dapat dilepaskan dengan bidang computer vision.

\subsection{Citra Grayscale}

Suatu citra dikatakan citra grayscale apabila suatu citra tidak memiliki warna RGB (Red, Green, Blue) maupun dapat dikatakan suatu citra yang memiliki nilai dari putih yang memiliki intensitas sangat besar sampai hitam/gelap yang memiliki intensitas lebih rendah. Citra grayscale terdiri dari $\mathrm{x}$ dan $\mathrm{y}$ dalam spasial koordinat dan mempunyai nilai intensitasnya masing-masing. Pada citra grayscale masing-masing gambar memiliki intensitas antara 0 (hitam/ gelap) hingga 255 (putih) dalam citra 8 bitnya [8].

\subsection{Deteksi Tepi Canny}

Deteksi tepi pada suatu citra menghasilkan tepi- tepi dari obyek citra yang bertujuan untuk menandai bagian yang menjadi detail citra, juga memperbaiki detail citra yang kabur karena error atau adanya efek dari proses akuisisi citra. Canny dikenal sebagai deteksi tepi yang optimal, algoritma ini memberikan tingkat kesalahan yang rendah. Beberapa metode deteksi tepi yaitu canny, sobel dan prewitt telah dibandingkan dengan hasil metode canny lebih baik dalam melakukan pengolahan kualitas citra untuk penghitungan deteksi tepi karena output dari metode canny memiliki batas dan tepi yang lebih jelas [9].

Salah satu algoritma deteksi tepi modern adalah deteksi tepi dengan menggunakan metode canny. Deteksi tepi canny ditemukan oleh Marr dan Hildreth yang meneliti pemodelan persepsi visual manusia. Ada beberapa kriteria pendeteksi tepian paling optimum yang dapat dipenuhi oleh algoritma canny :

1. Mendeteksi dengan baik (kriteria deteksi) Kemampuan untuk meletakkan dan menandai semua tepi yang ada sesuai dengan pemilihan parameter parameter konvolusi yang dilakukan. Sekaligus juga memberikan fleksibilitas yang sangat tinggi dalam hal menentukan ingkat deteksi ketebalan tepi sesuai yang diinginkan. 
2. Melokalisasi dengan baik (kriteria lokalisasi) Dengan canny dimungkinkan dihasilkan jarak yang minimum antara tepi yang dideteksi dengan tepi yang asli.

3. Respon yang jelas (kriteria respon) Hanya ada satu respon untuk tiap tepi. Sehingga mudah dideteksi dan tidak menimbulkan kerancuan pada pengolahan citra selanjutnya.

\subsection{Ekstraksi Ciri}

Pada tahap ini dilakukan ekstraksi fitur Invariant Moments yang berguna untuk mengambil atau mengekstraksi nilai-nilai dari suatu objek yang membedakan dengan objek lain. Metode ini dapat digunakan untuk ekstraksi ciri suatu citra digital yang mampu mengenali citra tersebut [10]. Dalam pengambilan nilai dari suatu citra digital dapat dilakukan menggunakan rumus sebagai berikut :

$\varnothing 1=\eta 20+\eta 02$

$\varnothing 2=(\eta 20-\eta 02) 2+(2 \eta 02) 2$

$\varnothing 3=(\eta 30-3 \eta 12) 2+(\eta 03+3 \eta 21) 2$

$\varnothing 4=(\eta 30+\eta 12) 2+(\eta 03+\eta 21) 2$

$\varnothing 5=(\eta 30-3 \eta 12)(\eta 03+\eta 21)[(\eta 30+\eta 12) 2-3(\eta 21+$

$\eta 03) 2]+(\eta 03-3 \eta 12)(\eta 03+\eta 21)[(\eta 03+\eta 12) 2-3(\eta 12$

$+\eta 30) 2]$

$\varnothing 6=(\eta 20-\eta 02)[(\eta 30+\eta 12) 2-(\eta 21+\eta 03) 2]+4 \eta 11$

$(\eta 30+\eta 12)(\eta 03+\eta 21)$

$\varnothing 7=(\eta 21-3 \eta 03)(\eta 30+\eta 12)[(\eta 30+\eta 12) 2-3(\eta 21+$ $\eta 03) 2]-(\eta 30-3 \eta 12)(\eta 21+\eta 03)[(\eta 03+\eta 21) 2-3(\eta 30+$ g12) 2$]$

Hasil perolehan ekstraksi fitur invariant moment ini akan digunakan di dalam proses pelatihan dan pengujian di algoritma k-nearest neighor untuk proses pengenalan citra ikan cupang. Hasil dari proses invariant moments pada citra ikan cupang crowntail dapat dilihat pada tabel 1.

Tabel 1. Nilai Invariant Moment Citra Ikan Cupang

\begin{tabular}{|c|c|c|c|c|c|c|c|c|}
\hline \multirow{2}{*}{ no } & \multirow{2}{*}{ Nems ienis } & \multicolumn{7}{|c|}{ Nette: Butraks: Cirt } \\
\hline & & mi & $\mathrm{m} 2$ & ms & ma & us & $\mathrm{ms}$ & $m$ \\
\hline 1 & crowntal & 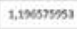 & 0,043497812 & Co:4asson: & 0,002289896 & satosere ar & $0,0500405 m$ & 1.2504ate o5 \\
\hline 2 & Desetinat & 0,762018นบ & 0,008010723 & 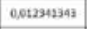 & 2.81446-05 & 212050600 & 8.7626et-66 & 4, $3465 \% .0 \mathrm{at}$ \\
\hline 3 & Ounboeser & 0,8055000139 & 0,11390273 & conoessizc & 0,052707874 & 134105e os & a, 050023339 & $4,40087 \div 06$ \\
\hline 4 & Hatmosen & 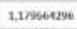 & e,04123ins & 0,0034/23an & 0,012549ve & 4,000175000 & 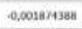 & -7.8asutces \\
\hline 8 & maver & 0.91295154 & $0,1603754,36$ & 0,00502015 & 0,0012144 & 2Anzre 06 & a.050212054 & s.0075nt of \\
\hline${ }^{\circ}$ & siber & a.ssnestan & 0,16youncos & opestasezon & 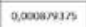 & -2 - & -0,000tก:3 & $-2,00200$ - O? \\
\hline 7 & wis & 0,206390266 & 0.250900037 & exsomingss & 0.0109409096 & $0.0005 \cos 40$ & 0.0000008643 & 9,000325454 \\
\hline
\end{tabular}

\subsection{K-Nearest Neighbor}

K-Nearest Neighbor (KNN) bekeja dengan cara mengklasifikasikan suatu objek yang memiliki kemiripan paling dekat dengan objek lainnya. KNN memiliki atribut yang diinisialisasikan sebagai $\mathrm{k}$, yaitu jumlah nilai tetangga yang dijadikan acuan pada klasifikasi k-nearest neighbor untuk dibedakan berdasarkan kelasnya. alasan dipilihnya metode k-nearest neighbor karena dapat melakukan klasifikasi terhadap objek berdasarkan data pembelajaran yang jaraknya paling dekat dengan objek tersebut sehingga hasilnya bisa lebih akurat [11].

Tahapan - tahapan dari K-Nearest Neighbor dijelaskan sebagai berikut :

1. Banyaknya parameter $\mathrm{K}$ yang dipakai pada aplikasi ada $7(\mathrm{~K}=1,2,3,4,5,6,7)$ di pertimbangkan berdasarkan banyak data.
2. Menghitung jarak antara data baru yang ditanyakan dengan seluruh sampel datapelatihandengan menggunakan metode eulidean distance.

3. Urutkan seluruh jarak berdasarkan jarak minimum dan tetapkan. persekitaran sesuai dengan nilai $\mathrm{K}$.

4. Sesuaikan klasifikasi dari kategori $\mathrm{Y}$ dengan persekitaran yang telah ditetapkan.

5. Gunakan kelas dengan jumlah terbanyak sebagai dasar menentukan kelas dari data baru yang ditanyakan.

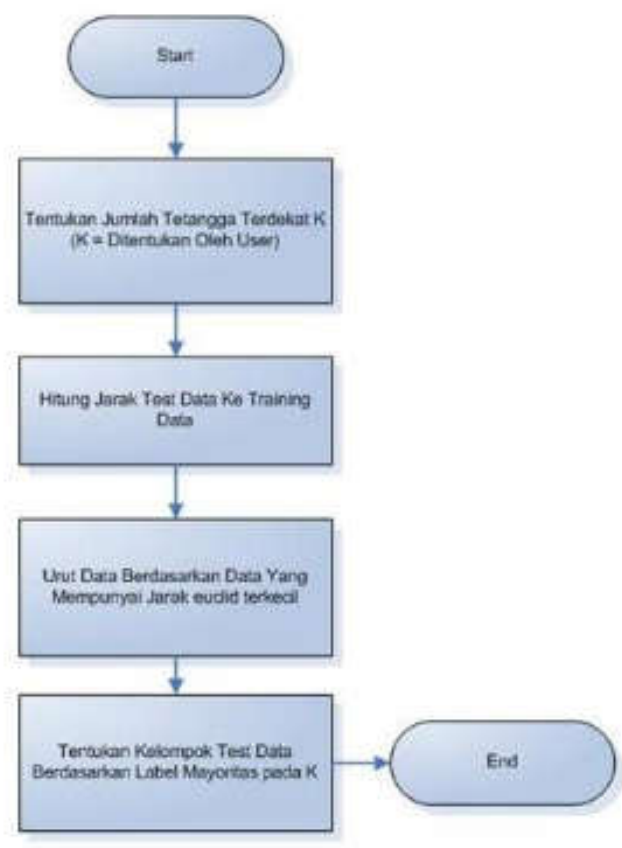

Gambar 1. K-Nearest Neighbor

\section{HASIL DAN PEMBAHASAN}

Metode yang digunakan pada penelitian ini adalah metode K-Nearest Neighbor untuk klasifikasi dalam menentukan jenis ikan cupang dan metode deteksi tepi Canny untuk meningkatkan penampakan garis batas suatu daerah atau objek dari ikan cupang agar tekstur ikan menjadi lebih jelas.

\subsection{Pengumpulan Data}

Data ikan cupang yang dibutuhkan dalam penelitian, dihasilkan dari beberapa sumber seperti buku, internet, dan para peternak ikan cupang. selanjutnya data tersebut akan dilakukan proses editing dengan cara mengubah background menjadi berwarna putih, kemudian ukurannya disamakan menjadi 500x500 piksel. Untuk jenisnya dibagi menjadi 7 jenis yaitu Crowntail, Doubletail, Dumboear, Halfmoon, Plakat, Slayer, Wild berdasarkan bentuk sirip dan ekor setiap jenis mengumpulkan 10 citra, Sehingga total data citra yang digunakan adalah 70 citra ikan cupang. Citra yang telah didapatkan akan diuji coba menggunakan $\mathrm{k}$-nearest neighbor dan deteksi tepi canny. Sebanyak 70 citra digunakan sebagai citra latih dan 20 citra digunakan sebagai citra uji. 


\subsection{Pembuatan Prototype}

Metode pengembangan sistem untuk prototype program yang akan dibuat adalah dengan menggunakan Extreme Programming (XP). Tahapan dalam metode extreme programming yaitu : Planning, Design, Coding, Testing.

\section{Planning}

Hasil dari tahap planning adalah sebagai berikut:

a) Perangkat keras yang dibutuhkan dalam pembuatan prototype program dapat dilihat pada tabel 2 .

Tabel 2. Kebutuhan Perangkat Keras

\begin{tabular}{|c|c|c|}
\hline No & Nama Komponen & Spesifikasi \\
\hline 1. & Processor & $\begin{array}{c}\text { Intel } 8 \text { Celeron } 8 \text { Processor N4020 } \\
\text { (Cache } 4 \mathrm{M} \text {, hingga } 2,80 \mathrm{GHz})\end{array}$ \\
\hline 2. & Memory (RAM) & 4 GB DDR4 \\
\hline 3. & Hardisk & 1 TB \\
\hline 4. & Monitor & $\begin{array}{r}\text { 14 Inch HD LED backlit, Panel with } \\
4 \% \text { NTSC } 1366 \times 768\end{array}$ \\
\hline 5. & Kamera & VGA Web Camera \\
\hline 6. & Mouse & Standart PS/2, USB \\
\hline 7. & Printer & Standart PS/2, USB \\
\hline
\end{tabular}

b) Perangkat lunak yang dibutuhkan adalah sistem operasi, matlab R2016a, Microsoft office word 2019.

c) Kebutuhan masukan atau input yang dibutuhkan dalam program yang dibuat adalah berupa data citra ikan cupang dalam format jpg.

d) Output yang dibutuhkan dalam program adalah menampilkan jenis ikan cupang yang telah diuji coba.

2. Design

Pada tahap ini dibuat desain sistem serta desain interface yang sesuai dan mudah untuk digunakan agar informasi yang didapat mudah dipahami. Hasil dari tahap design adalah sebagai berikut :

a) Desain Sistem

Flowcart memiliki fungsi untuk memberikan gambaran mengenai sistem yang akan dibuat pada penelitian. Pada bagian ini akan dijelaskan mengenai proses pengolahan data yang berupa citra yang kemudian diolah menggunakan image processing sehingga dapat menghasilkan kemampuan mengenali suatu objek. Gambaran flowchart dapat dilihat pada gambar dibawah :

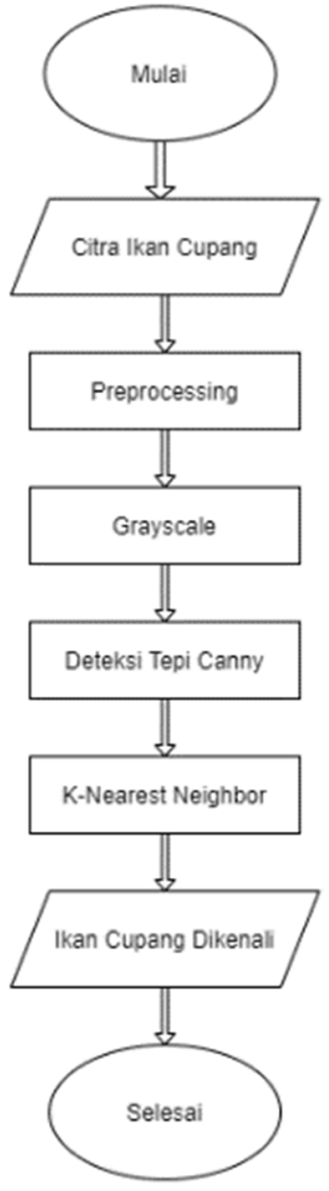

Gambar 2. Flowchart sistem

b) Desain Interface

Desain interface yang akan dibuat dapat dilihat pada gambar dibawah :

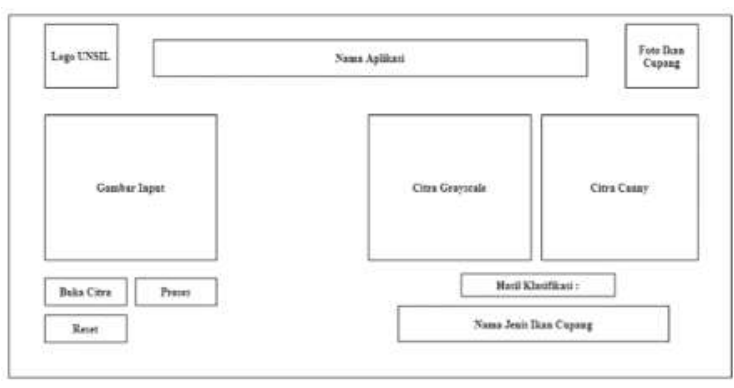

Gambar 3. Desain interface

Keterangan :

1) Tombol "Buka Citra" berfungsi untuk mencari serta memasukan citra ikan cupang yang akan diuji coba. Citra tersebut akan ditampilkan pada axes "Buka Citra".

2) Tombol "Proses" berfungsi untuk memproses citra yang akan menghasilkan citra grayscale dan citra deteksi tepi canny yang akan di tampilkan pada axes. Kemudian akan menghasilkan output nama jenis ikan cupang pada kolom "Hasil Klasifikasi".

3) Tombol "Reset" berfungsi untuk proses untuk melakukan reset terhadap proses yang sudah dilakukan sebelumnya. 


\section{Coding}

Tahap selanjutnya adalah tahap coding. Pada tahap preprocessing citra, langkah yang dilakukan terhadap data latih serta data uji adalah sama. Langkah-langkah pengolahan citra adalah sebagai berikut :

1) Menyiapkan Citra Ikan Cupang

Citra ikan cupang yang disiapkan sebanyak 90 citra yang terdiri dari 7 jenis ikan cupang yang telah dibagi berdasarkan bentuknya kemudian diproses menggunakan aplikasi edit foto agar backgroundnya berwarna putih. Lalu disamakan dimensinya menjadi 500x500 piksel.

2) Menyiapkan Data Latih dan Data Uji

Citra ikan cupang yang sudah diubah backgroundnya menjadi berwarna putih dan disamakan dimensinya menjadi 500x500 piksel, selanjutnya dibagi menjadi dua jenis data yaitu data latih (training) serta data uji (testing). Data latih terdiri dari 10 citra untuk setiap jenis ikan cupang, sehingga jumlahnya menjadi 70 citra. Data Uji terdiri dari 2 citra untuk masing - masing jenis ditambah 6 citra baru, sehingga jumlahnya menjadi 20 citra. Data untuk pelatihan disimpan dalam satu folder dengan nama Data Latih. Data untuk pengujian disimpan pada folder dengan nama Data Uji. Contoh citra yang akan diproses dapat dilihat pada gambar 4 .

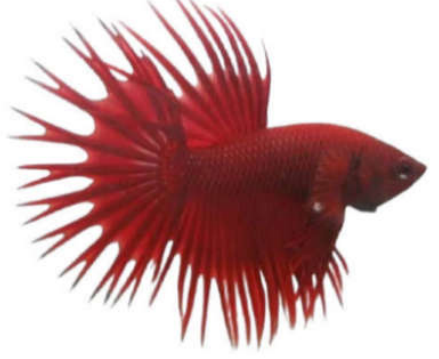

Gambar 4. Citra preprocessing

c) Citra Grayscale

Citra yang diperoleh dari hasil editing merupakan citra warna yang terdiri dari tiga jenis warna (Red, Green, Blue) dalam satu pikselnya, sehingga perlu melakukan perubahan warna menjadi grayscale agar dapat diproses untuk tahap selanjutnya. Perubahan citra menjadi citra grayscale bertujuan mengubah tiga warna yang memiliki 3 nilai dalam satu piksel citra (Red, Green, Blue) menjadi hanya mempunyai satu nilai untuk setiap pikselnya. Hasil dari citra grayscale dapat dilihat pada gambar dibawah :

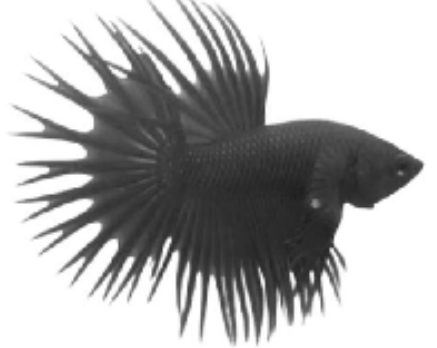

Gambar 5. Citra grayscale d) Deteksi Tepi Canny

Deteksi tepi dilakukan setelah proses grayscale citra, Deteksi tepi canny digunakan untuk meningkatkan penampakan garis batas suatu daerah atau objek dari ikan cupang, agar tekstur ikan menjadi lebih jelas. Hasil dari deteksi tepi canny dapat dilihat pada gambar 6 .

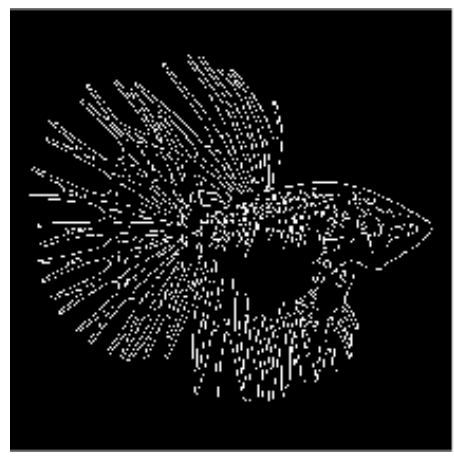

Gambar 6. Citra deteksi tepi canny

e) K-Nearest Neighbor (K-NN)

Pada tahap ini, training dan testing data citra dilakukan dengan menggunakan k-nearest neighbor. Nilai yang dihasilkan kemudian dijadikan sebagai nilai input untuk melatih data sebanyak 70 citra yang akan menghasilkan nilai basis pengetahuan mengenai jenis ikan cupang. Untuk proses testing pada k-nearest neighbor, menggunakan sebanyak 20 citra ikan cupang dengan proses yang sama, basis pengetahuan diambil dari proses pelatihan yang telah dilakukan dengan data latih sebelumnya. Selanjutnya proses pengujian dituangkan ke dalam interface pada matlab dengan input citra dari data training maupun testing yang akan menghasilkan output berupa jenis ikan cupang yang diuji.

Penelitian ini bertujuan untuk mengklasifikasikan ikan cupang ke dalam 7 jenis, yaitu jenis Crowntail, Doubletail, Dumboear, Halfmoon, Plakat, Slayer, dan Wild. Untuk ekstraksi ciri disini saya menggunakan metode moment invariant dimana jumlah data dibagi menjadi 7 dimulai dari M1, M2, M3 M4, M5 M6, dan M7. Data latih yang dipakai pada penelitian ini berjumlah 70 sampel terdiri dari 10 citra untuk setiap jenis ikan cupang. Data ekstraksi ciri dapat dilihat pada tabel 3 .

Tabel 3. Data Ekstraksi Ciri

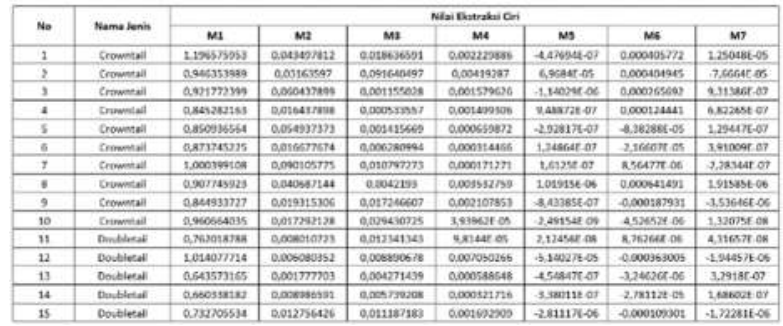

Proses tahapan klasifikasi menggunakan metode KNearest Neighbor untuk menentukan jenis ikan cupang akan dijelaskan sebagai berikut : 
1. Menentukan banyaknya parameter $\mathrm{K}$ yang akan dipakai, pada penelitian ini banyaknya parameter $\mathrm{K}$ yang akan dipakai adalah $\mathrm{K}=7$.

2. Selanjutnya kita cari terlebih dahulu jarak data yang akan dievaluasi, yaitu $\mathrm{r}=(1,18277,0,311183$, 0,025375, 1,72E-02, 3,02E-05, -5,72E-03, 4,94E-05) terhadap setiap data pelatihan dengan menggunakan Euclidean. Jarak Euclidean data evaluasi r pada data pelatihan ke-i (Xi) dirumuskan sebagai berikut :

$$
\mathrm{d}_{\mathrm{ik}}=\sqrt{\sum_{\mathrm{j}=1}^{\mathrm{m}}\left(\mathrm{x}_{\mathrm{ij}}-\mathrm{r}_{\mathrm{kj}}\right)^{2}}
$$

Untuk data jarak euclidean dapat dilihat pada tabel 4.

Tabel 4. Data Jarak Euclidean

\begin{tabular}{|c|c|c|c|c|c|c|c|c|c|c|c|c|c|c|c|c|}
\hline & & \multirow{2}{*}{\multicolumn{7}{|c|}{ 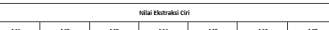 }} & & & & & $\cos 00 y$ & & & \\
\hline we & & & & & & & & 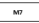 & & $\mathrm{m}$ & 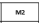 & & $\mathrm{m}$ & N5 & ws & \\
\hline & 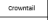 & 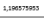 & 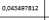 & rossens & 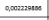 & Leterestor & 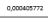 & 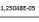 & & \begin{tabular}{|l|l|l|l|l} 
\\
\end{tabular} & 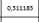 & & & & & \\
\hline & & & 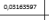 & & & $(m-\infty)$ & nomoseserser & resanters & anses & $\begin{array}{l}1.1 \times 27 \\
\end{array}$ & ostites & 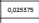 & $1.7 \pi \times 02$ & tancests & 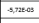 & \\
\hline & conotatel & asmmentem & 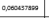 & 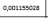 & 0 & 4 & 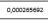 & ansorere & 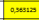 & inar & os anow & (cocests & 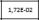 & $\sqrt{n \pi x \rightarrow \infty}$ & 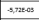 & Astrest \\
\hline & consalat & 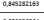 & mastrate & 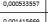 & nambersecen & pastineter & 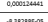 & 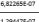 & 型 & ${ }^{3, \mathrm{~m} z}$ & 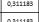 & 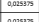 & trater & 型 & 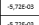 & tarter. \\
\hline & & & & & & & 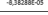 & 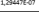 & & 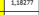 & & 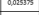 & Titoz: & 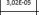 & & \\
\hline & 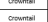 & 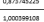 & 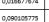 & 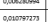 & 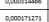 & 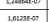 & 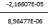 & 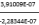 & 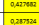 & 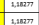 & 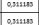 & cescoss & 1) & ateres & 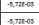 & tsated \\
\hline & conerat & canteres & 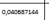 & oxatises & 000532159 & 1,09151606 & conoctaters & astsctos & 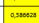 & 1,127 & wastax & 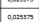 & 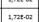 & 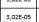 & & tsate \\
\hline & & & & & & & & & chanes & 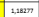 & & , & 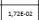 & , wexs & & Latecter \\
\hline & & & & & & eisyesed & 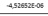 & 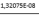 & . & $\operatorname{tin} n$ & grames & ceserst & zateaz & | & & \\
\hline & & & & & tatem & tasteres & 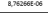 & 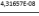 & 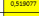 & & 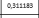 & 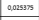 & intear & & & \\
\hline & conetral & 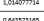 & acosesess & aroserosts & 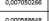 & 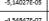 & 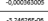 & 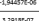 & Dassant & 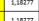 & Castarata & 0 & 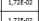 & 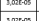 & 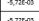 & 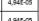 \\
\hline & & & & & & & & & & & & & & & & \\
\hline & & & & & & & & & & & & & & & |ments & tancen \\
\hline
\end{tabular}

3. Selanjutnya data diurutkan berdasarkan jarak apabila kita tetapkan nilai $\mathrm{K}=7$, maka kita ambil 7 jarak terpendek. Hasil data jarak euclidean yang telah diurutkan dapat dilihat pada tabel 5 .

Tabel 5. Data Jarak Euclidean (Telah Diurutkan)

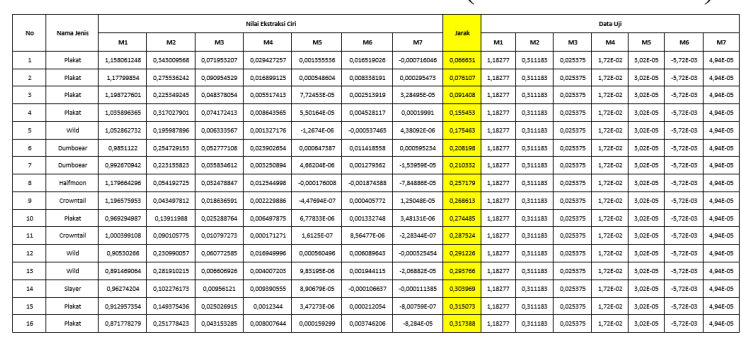

4. Pada urutan pertama sampai ketujuh, ada 4 jenis plakat, sehingga untuk data evaluasi $\mathrm{r}=(1,18277$, $0,311183,0,025375,1,72 \mathrm{E}-02,3,02 \mathrm{E}-05,-5,72 \mathrm{E}-03$, 4,94E-05) termasuk dalam jenis plakat.

f) Implementasi Sistem

Tahapan ini berisi mengenai implementasi deteksi tepi canny dan k-nearest neighbor untuk menentukan jenis ikan cupang. Implementasi proses-proses dalam alur penelitian deteksi tepi canny dan k-nearest neighbor disajikan ke dalam interface dengan menggunakan Matlab R2016a, dapat dilihat pada gambar 7 .

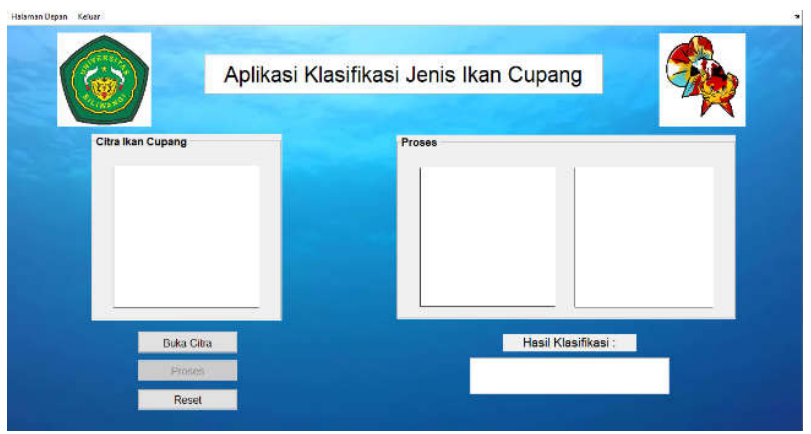

Gambar 7. Interface program g) Analisis dan Hasil

Tahapan pertama yaitu melakukan proses pencarian data untuk diuji yang akan digunakan. Data uji yang digunakan pada penelitian ini menggunakan format jpg. Selanjutnya data yang telah diinputkan akan melalui beberapa proses pengolahan citra, diantaranya konversi citra ke dalam citra grayscale kemudian citra akan di konversi ke citra deteksi tepi canny. Output dari proses tersebut dapat dilihat pada gambar 8 .

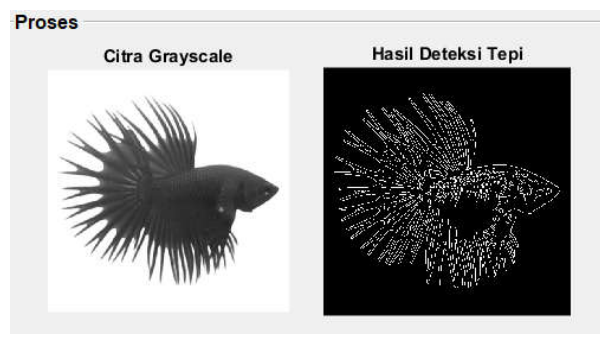

Gambar 8. Hasil pengolahan citra

Citra hasil deteksi tepi canny kemudian akan menjadi nilai untuk dilakukan proses training pada k-nearest neighbor. Hasil dari training data citra tersebut akan menjadi acuan untuk menghasilkan output data ikan cupang sesuai dengan proses training. Output yang ditampilakan berupa jenis ikan cupang yang terdeteksi dapat dilihat pada gambar dibawah :

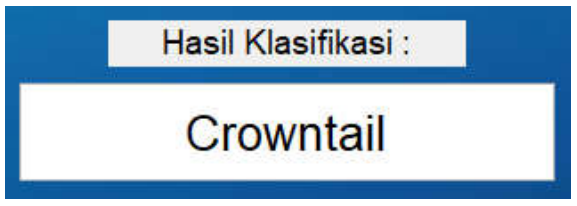

Gambar 9. Output klasifikasi ikan cupang

4. $\quad$ Testing

Pada tahap pengujian sistem, dilakukan testing untuk melihat kemungkinan kesalahan pada fungsi yang terdapat dalam interface program dengan menggunakan pengujian akurasi. Secara keseluruhan fungsi sistem yang diuji dapat berjalan dengan baik dan sesuai dengan yang diharapkan.

Pada penelitian ini dilakukan uji coba menggunakan 90 data citra yang terbagi ke dalam data training (latih) dan data testing (uji). Pada data training, setiap jenis menggunakan 10 data citra sehingga berjumlah 70 data. Sedangkan pada data uji ada sebanyak 20 citra.

1) Data training (data latih)

Data latih yang digunakan berjumlah 70 data, dapat dilihat pada gambar 10 .

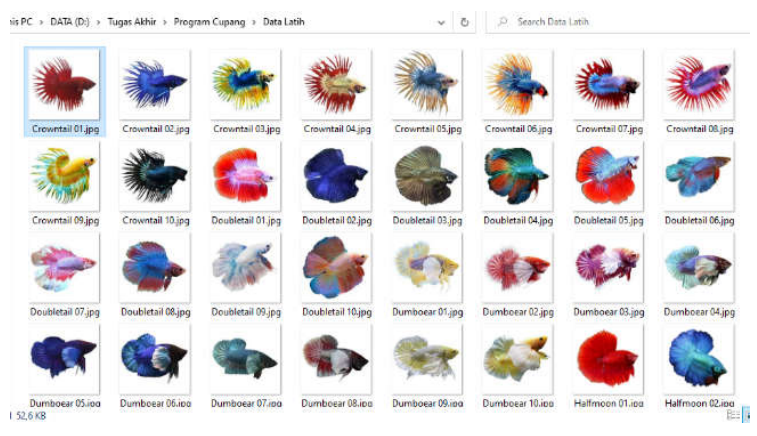


Gambar 10. Citra data latih

Dari 70 data yang di uji coba, menghasilkan akurasi pelatihan k-nearest neighbor sebesar 68,5714\%. Hasil uji ditampilkam pada tabel 6 .

Tabel 6. Hasil Uji Data Latih

\begin{tabular}{|c|c|c|c|c|c|c|c|c|c|c|c|c|c|c|}
\hline \multirow{2}{*}{ No. } & \multirow{2}{*}{ Input Jenis } & \multicolumn{10}{|c|}{ Output } & \multirow{2}{*}{ Dikenali } & \multirow{2}{*}{$\begin{array}{c}\text { Tidak } \\
\text { Dikenali }\end{array}$} & \multirow{2}{*}{ Akurasi } \\
\hline & & 1 & 2 & 3 & 4 & 5 & 6 & 7 & 8 & 9 & 10 & & & \\
\hline 1. & Crowntail & 1 & 1 & 1 & 1 & 1 & 1 & 1 & 1 & 1 & 1 & 10 & 0 & $100 \%$ \\
\hline 2. & Doubletail & 1 & 1 & 1 & 1 & 1 & 1 & 1 & 1 & 1 & 1 & 10 & 0 & $100 \%$ \\
\hline 3. & Dumboear & 1 & 1 & 1 & 1 & 1 & 1 & 1 & 1 & 1 & 1 & 10 & 0 & $100 \%$ \\
\hline 4. & Halfmoon & 0 & 1 & 0 & 0 & 0 & 1 & 0 & 0 & 0 & 0 & 2 & 8 & $20 \%$ \\
\hline 5. & Plakat & 1 & 1 & 1 & 1 & 1 & 1 & 0 & 1 & 1 & 1 & 9 & 1 & $90 \%$ \\
\hline 6. & Slayet & 1 & 0 & 0 & 0 & 1 & 1 & 1 & 0 & 0 & 1 & 5 & 5 & $50 \%$ \\
\hline 7. & Wild & 0 & 0 & 0 & 1 & 0 & 0 & 1 & 0 & 0 & 0 & 2 & 8 & $20 \%$ \\
\hline \multicolumn{12}{|c|}{ Jumlah } & 48 & 22 & \\
\hline \multicolumn{14}{|c|}{ Rata - rata } & $68,5714 \%$ \\
\hline
\end{tabular}

Hasil uji coba pada data latih menunjukan hasil yang beragam, total data yang dapat dikenali dengan dengan baik adalah 48 ikan dan 22 ikan tidak dapat dikenali dengan baik. Akurasi yang dihasilkan rata-rata sebesar $68,5714 \%$. Jenis cupang yang dapat dikenali dengan baik adalah jenis Crowntail, Doubletail, dan juga Dumboear. Jenis yang tidak dikenali dengan baik dapat disebabkan oleh bentuk sirip dan ekor ikan cupang yang tidak menentu.

2) Data testing (data uji)

Data uji menggunakan 20 data citra, dapat dilihat pada gambar berikut :

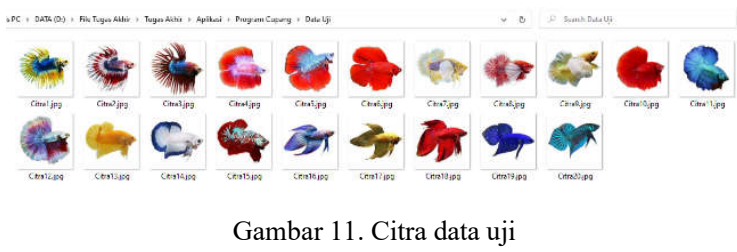

Proses pengujian sama dengan pada data latih, hanya saja untuk proses pelatihan menggunakan data yang ada pada data latih. Dari 20 data yang di uji coba, menghasilkan akurasi pelatihan k-nearest neighbor $70 \%$. Hasil uji ditampilkan pada tabel 7.

Tabel 7. Hasil Uji Data Uji

\begin{tabular}{|c|c|c|c|c|c|c|c|}
\hline \multirow[b]{2}{*}{ No. } & \multirow[b]{2}{*}{ Input Jenis } & \multicolumn{3}{|c|}{ Output } & \multirow[b]{2}{*}{ Dikenali } & \multirow{2}{*}{$\begin{array}{c}\text { Tidak } \\
\text { Dikenali }\end{array}$} & \multirow[b]{2}{*}{ Akurasi } \\
\hline & & 1 & 2 & 3 & & & \\
\hline 1. & Crowntail & 1 & 1 & 1 & 3 & 0 & $100 \%$ \\
\hline 2. & Doubletail & 1 & 1 & 0 & 2 & 1 & $66,66 \%$ \\
\hline 3. & Dumboear & 1 & 1 & 1 & 3 & 0 & $100 \%$ \\
\hline 4. & Halfmoon & 0 & 1 & 0 & 1 & 2 & $33,33 \%$ \\
\hline 5. & Plakat & 1 & 0 & 1 & 2 & 1 & $66,66 \%$ \\
\hline 6. & Slayer & 1 & 1 & 0 & 2 & 1 & $66,66 \%$ \\
\hline 7. & Wild & 1 & 0 & & 1 & 1 & $50 \%$ \\
\hline \multicolumn{5}{|c|}{ Jumlah } & 14 & 6 & \\
\hline \multicolumn{7}{|c|}{ Rata - rata } & $70 \%$ \\
\hline
\end{tabular}

Sama dengan pada data latih, akurasi yang dihasikan bergantung pada data citra yang diinput. Akurasi yang dihasilkan rata-rata sebesar $70 \%$. Jenis ikan cupang yang dapat dikenali dengan baik adalah jenis Crowntail dan Dumboear.

\subsection{Evaluasi Hasil}

Berdasarkan penelitian yang telah dilakukan kan, sesuai dengan tujuan penelitian bahwa metode K-Nearest
Neighbor dan deteksi tepi Canny dapat diterapkan pada penentuan jenis ikan cupang. Kelebihan pada sistem ini adalah mampu menghasilkan akurasi yang cukup baik yaitu $68,5714 \%$ untuk data latih serta $70 \%$ pada data uji. Informasi yang disampaikan dapat dipahami dengan mudah serta semua fungsi berjalan dengan baik. Kekurangan pada sistem uji coba hanya dilakukan pada matlab, tidak dibuat berupa aplikasi.

\section{KESIMPULAN DAN SARAN}

Klasifikasi ikan cupang menggunakan metode knearest neighbor dan untuk ekstraksi fitur bentuknya menggunakan metode deteksi tepi canny berhasil diimplementasikan. Data yang diperoleh dari hasil klasifikasi berupa data citra grayscale, citra deteksi tepi canny dan output jenis ikan cupang. Pengujian yang telah dilakukan menggunakan data latih terhadap 70 citra menghasilkan nilai akurasi rata-rata sebesar 68,5714\%, dengan jumlah data yang terdeteksi dengan baik adalah sebanyak 48 data dan 22 data tidak terdeteksi dengan baik. Pengujian yang telah dilakukan menggunakan data uji terhadap 20 citra menghasilkan nilai akurasi rata-rata sebesar $70 \%$, dengan jumlah data yang terdeteksi dengan baik adalah sebanyak 14 data dan 6 data tidak terdeteksi dengan baik. Hasil akurasi yang kurang baik dapat disebabkan oleh bentuk sirip dan ekor ikan cupang yang tidak menentu.

\section{DAFTAR PUSTAKA}

[1] N. C. Y. Setiawan, "Penerapan Metode Naive Bayes Untuk Menentukan Jenis Ikan Cupang Hias,” Jurnal Universitas Nusantara PGRI Kediri, PP. 1-8, 2017.

[2] S. Budi, "Kombinasi Metode Fordward Chaining Dan Certainty Factor Untuk Mendiagnosa Penyakit Pada Ikan Cupang," Jurnal Universitas Nusantara PGRI Kediri, PP. 1-6, 2017.

[3] M. A. Ashari, "Penentuan Juara Kontes Ikan Cupang Dengan Menggunakan Metode Promethee,” Jurnal Universitas Nusantara PGRI Kediri, PP. 1-8, 2019.

[4] J. W. Yudha and A. W. Kurniawan, "Pengenalan Motif Batik Menggunakan Deteksi Tepi Canny Dan K-Nearest Neighbor," Techno.COM, Vol. 3 No. 4, PP. 251-262, 2014.

[5] I. Hastuti, "Perbandingan Metode Deteksi Tepi Menggunakan Metode Canny, Prewitt Dan Sobel Pada Image Ikan," Prosiding SNRT (Seminar Nasional Riset Terapan), PP. 129-137, 2016

[6] J. Moedjahedy, A. Bokang, and A. Raranta, “Aplikasi Pengenalan Ikan Hias Predator Air Tawar Menggunakan Teknologi Augmented Reality Berbasis Android," Cogito Smart Journal, Vol. 3 No. 1, PP. 91-99, 2017.

[7] B. A. Masse and A. N. Ainun, "Perancangan Aplikasi Magic Book Pengenalan Hewan Air Dengan Teknologi Augmented Reality," Jurnal Elektronik 
Sistem Informasi dan Komputer, Vol. 4 No. 1, PP. 47-62, 2018.

[8] R. Andrian, S. Anwar, A. M. Muhammad, and A. Junaidi, "Identifikasi Kupu-Kupu Menggunakan Ekstraksi Fitur Deteksi Tepi (Edge Detection) dan Klasifikasi K-Nearest Neighbor (KNN)," Jurnal Teknik Informatika dan Sistem Informasi, Vol. 5 No. 2, PP. 234-243, 2019.

[9] A. Wulandari, S. Andryana, and A. Gunaryati, "Pengenalan Ikan Hias Laut Pada Anak Usia 3 Tahun Dengan Metode Marker Based Tracking Berbasis Augmented Reality," Jurnal Teknologi \& Manajemen Informatika, Universitas Nasional, Vol. 5 No. 1, PP. 1-8, 2019.

[10] A. Y. Nugroho, "Sistem Pendukung Keputusan Dalam Menentukan Pemenang Kontes Ikan Cupang Hias Menggunakan Metode GAP Profile Matching," IT Journal, Vol. 4 No. 1, PP. 99-108, 2016.

[11] H. Surahman, A. Fuja, I. Rubandi, and Willy, "Pengenalan Jenis Pempek Menggunakan Metode Canny \& K-Nearest Neighbor (KNN) Berdasarkan Bentuknya,” Jurnal STMIK GI MDP, PP. 1-11, 2017.

\section{BIODATA PENULIS}

Penulis Pertama

Fajar Shidiq

Mahasiswa Prodi Informatika Universitas Siliwangi

Tasikmalaya

Penulis Kedua

Eka Wahyu Hidayat, S.T., M.T

Dosen Prodi Informatika Universitas Siliwangi

Tasikmalaya

Penulis Ketiga

Neng Ika Kurniati, S.Si., M.Cs

Dosen Prodi Informatika Universitas Siliwangi

Tasikmalaya 